GUEST EDITORIAL

\title{
Teaching and Learning in Medicine
}

\author{
GARETH HOLSGROVE
}

\section{INTRODUCTION}

About a quarter of a century ago, medicine discovered education. Prior to that, apart from a tiny number of exceptions, which usually took the form of outstanding individuals rather than excellent institutions, training for doctors had very little in common with good educational practise. In fact in many instances it violated even the most basic educational principles. Good doctors were produced despite the system, not because of it.

Doctors have to learn a great deal at both the undergraduate and postgraduate stages of their careers, and today it is universally acknowledged that their professional education continues from the first day at medical school until the last day in practise. Moreover, as both the ancient version and Lasagne's 1964 revision of the Hippocratic Oath remind us, Doctors have an obligation to teach those who will follow them. In other words, there is a professional expectation that all Doctors who have taken the Oath will participate in the delivety of medical education. Yet, despite this obligation, medical education, as a discipline in its own right, is such a recent innovation that many medical schools and professional medical bodies still lack a medical education department. This is extraotdinary when one considets that medial education is the cote business of medical schools and a major aspect of the services provided by many of the professional organizations.

This editorial provides an oppottunity to outline some historical aspects of how medical education has grown as an academic discipline, and to provide an insight into some principles of teaching and learning in medicine.

\section{SOME MILESTONES IN MEDICAL EDUCATION}

The past 20 years or so have seen the expansion of medical education as a recognised academic disciptine and this has led to massive improvements in the training of Doctors and other healthcare workers across the world. Until the turn of the $20^{\text {th }}$ century, these improvements were predominantly in undergraduate medical education and typically took the form of fundamental changes to the curriculum. More recently the focus has increasingly shifted towards postgraduate education and training. However, developments in undergraduate medical education continue and there is little sign that the pace or volume of change at any stage of medical education will diminish in the foreseeable future.

Modernisation of the undergraduate curriculum was pioneered by forward-looking medical schools mainly in the USA, Canada and Australia. The UK was slow to follow suit, and some other countries have been even slower, but now curriculum changes have spread to many countries, particularly those whose medical education follows the US or UK models. These changes were mainly in response to the two main and persistent criticisms of traditional medical education - that students were often learning inapproptiate things, and they were often using very poor strategies to learn them. For example, the first two years of the traditional course was spent almost exclusively learning basic medical science, but in isolation from the clinical experience that would make it meaningful. Moreover, medical students were often expected to learn things in excessive detail - the Kreb's cycle springs to mind, and many Doctors will recall the hours spent learning neuroanatomy, procceding through the brain in $1 \mathrm{~mm}$ steps with the learner's own brain scarcely being engaged at all except as a repository of anatomical names. The process of excessive factual overload in learning (or, to more accurately describe what was happening, committing facts to memory) was rypically followed by high-stakes examinations that tested mainly factual recall. Srudents responded to this in a highly predictable way. They resorted predominantly to rote-learning and restricted what they learned to things that they thought might come up in the examinations. This characteristic is known technically as consequential validity - the effect that examinations have on what and how students learn. Since for most people rote-leaming tends to be difficult, boring and temporary, students who were forced to resort to it found it hard work, uninteresung and forgot much of what they had learned shortly after (or, in unfortunate cases, shortly before) the examinations.

However, these adverse characteristics of the traditional curriculum and examinations were not suddenly and dramatically discovered a quarter of a century ago. Serious doubts about the way Doctors were trained had been articulated by individuals and in official documents for a surprisingly long time. For example, a minute of the General Medical Council (GMC) as long ago as 1869 warned about the dangers of an excessively burdensome curriculum and Thomas Huxley, in an address in 1876, said that "the burden we place on the medical student is far too heavy....A system of medical education that is actually caiculated to obstruct the acquisition of sound knowledge and to heavily favour the crammer and the grinder is a disgrace".

The fact that next to nothing happened by way of improvement over the next century caused the GMC to make recommendations in 1957, and again in 1967, to reduce the students' factual foads. They said that this was important so that the memorising and reproduction of factual data did not interfere with a critical study of the principles and development of independent thought. Once again, though, this criticism of the medical curriculum was largely ignored and the CMC's views were reiterated yet again in their Recommendations on Basic Medical Fiducation in 1980.

Despite these clear, repeated and authoritative exhortations, still they were not 
heeded in the UK for almost another decade. Finally, in 1990, when it became increasingly clear that this time the GMC would not allow their requirements to be ignored, a new undergraduate curriculum was introduced jointly by the medical schools of St Bartholomew's and the Royal London Hospitals. This was the first curriculum in the UK to be based specifically on the GMC recommendations - albeit well over a century after their predecessors were first abled.

The principles set out by the GMC included a reduction in factual overload, a curriculum that woujd foster independent, collaborative and life-long learning, an emphasis on skills in communication and reamworking, and an integration of clinical medicine with the underpinning scientific principies. In other words, almost the opposite characteristics to those of the unditional undergraduate medical curriculum.

\section{A MOdern CuRRICuLuM}

After more than a century of resisance to changing the way doctors were trained, the introduction of the new curriculum in London suddenly spearheaded a series of far reaching changes that has now influenced almost cvery facet of medical education in the UK. There are two main reasons for this. The first is that the changes make educational sense. Then, enlightened by modern educational philosophy, theory and research, and by the time they came to be implemented in the UK they had been proved in practise in other countries. In fact, developments at several overseas medical scherols, particularly Newcastle in Australia and Maastricht in the Netherlands, were taken as models for the new Bart's/Royal London curriculum. The second reason that they have been successful and influential is that acuive steps were taken to promote and implement them. Fot example, they were championed tocally by several key members of faculty. particularly the Dean at St Bartholemew's Medical School (generally known as Bart's), the outstanding Lesley (now Dame Lesicy) Rees. They were also promoted nationally by the then Chief Medical (Officer, Siz Kenneth Calman.

Here, then, we find our two golden rules for high quality medical education at both undergraduate and postgraduate levels - it must be based on sound principles, and is most likely to prove successful when inspined and supported by excellent leadership. This, in turn, goes on to explain why many of the best medical schools and professional bodies have both excellent leadership and deparments of medical education. However, before moving on, it is worth looking at leadership at Bart's and the Royal London, and mationally under Kenneth Calman, in a bittle more detail.

Lesley Rees became Dean at Bart's early in the curriculum planning process that had been initiated by her predecessor lan Kelsey Fry. An important basic principle that was agreed, though not without considerable dissent, was that nobody over $\mathbf{5 0}$ years of age could be on any of the committees involved in planning and implementing the new curriculum. This proved to be a major factor in the success of the design and introduction of the curriculum, since only people who were likely to be major stakeholders - which later came to include medical students themselves - were involved in making the major decisions.

The curriculum that resulted utilised modern learning methods - principally selfdirected learning - and adopted a modular design based on body systems. Cote modules had vites such as 'Muscle, Bone and Joint' 'Blood' and 'Nutrition'. There was also a 'Community Module' and, in the first two years of the course, most of the core modules were taken by both medical and dental students working together. The core curriculum was supplemented by optional modules, which students could select from a lange number on offer. These included some research modules. One group, for example, researched their fellow students' preferred learning methods and, based on their findings, developed a workshop on 'how to study to become a Doctor' which they then $\tan$ for incoming students. This group subsequently delivered a paper on their project at an international medical education conference in the Netherlands. Another group made an information video about 'Glue Far' (secretory outis media) for parents and teachers. This subsequendy won 2 prize at the British Medical Association Fitm and Video Competition - the first medical student production to receive such an award.

At the national level, the Chief Medical Officer established the Undergraduate Medical Curciculum Implementation Support Scheme (UMCISS). This established a framework for educational expertise to be available to all the medical schools in England, Wales and Northern Ireland and has led to the establishment of dedicated departments of medical education at many UK medical schools. The UMCISS scheme proved to be a remarkable success, particularly when so much was achieved at such remarkably low cost. Indeed, in a personal conversation, Sir Kenneth Calman said that he regards LMCISS as one of his most important achievements as Chief Medical Officer.

The GMC documents, as we have seen, emphasised the fundamental (and longignored) principle that the curriculum must not be over-burdened, either with quantity or with purely factual information. Excessive quantity is likely to lead to selective learning. Students, unabie to cope with learning everything, will learn either the bits that interest them or, more probably, the things they expect to be asked about in examinations. Excessive amounts of factual information will lead to short-lived rote learning. Neither excessive quantity nor factual overload is educationally defensible and we ate now much more willing to accept that the object of the curriculum is not to pack in the whole of human knowledge on the subject. This leads us to two related issues - how to make the curriculum relevant and how to promote effective and appropriate learning.

A good approach to making the curriculum relevant is to establish what we intend the students to know and do after completing it, and then to design a curriculum that leads them logically along the steps necessary to achieve these intended outcomes. This principle does not just apply to the whole curriculum, it applies to any teaching and learning whether is is planned, like a lecture, or opportunistic at the bedside, in clinic or theatre. An important principle in the design and delivery of any medical curriculum is to ensure that theoty is learned in relarion to the context to which it is relevant, rather than requiring the facts 
to be leamed first in isolation. After all, if doctors are learning something, there must be a pracrical reason. This will usually be a clinical reason, but it might be sometimes be a legal, managerial or administrative one. Placing theory within the context of its practical application is likely to make the curriculum both relevant and interesting and this will stimulate effective learning

\section{LEARNING AND ASSESSMENT}

Another way to promote effective learning is to ensure that assessments support learning. Medical students at both undergraduate and postgraduate levels are among the most exam-driven students of all, and this characteristic tends to be seen worldwide. Therefore, because they are taken so seriously and shape what students actually learn, as opposed to what their teachers think they are learning, well designed assessments support good learning practises whereas poor examinations promote bad ones. Well designed assessments have several important characteristics. They sample many 'essential' areas of the curriculum, several 'important' areas, a few 'supplementary' ones to reward the high flyers. They do not waste valuable learning and testing resources assessing trivial or unimportant things. Furthermore, good medical exams assess performance and competence, not just knowledge. Where knowiedge is assessed, it is best done by examining application, rather than simply recall. Good assessments are also transparent, fair, and provide individual feedback to each student. Good formal, high-stakes examinations must also be supported by psychometric analysis to establish their reliability and to identify any dysfunctional items so that they can be removed.

\section{TEACHERS AND LEARNERS}

Teachers also have an important part to play in promoting effective learning. The best teachers are not 'founts of all wisdom' though the temptation to be seen as such, for novice and world authority alike, can be difficult to resist. This may be particularly so if part of their ritle is 'lecturer' - because this almost demands that they give lectures. However, as someone once observed, a lecture can often be the process whereby information goes from the lecturer's notes to the student's notes without going through the brains of either. There are good lectures, of course, but there are many more bad ones. They may be poorly prepared, set at a level (usually too high) that is inappropriate for the audience, attempt to cover too much material and thus become too long or too rushed, be incompetently delivered, and not make appropriate use of well-designed visual aids, handouts etc.

Good teaching is not a one-way process. Nor is it an interrogation - a point that clinical teachers often forget. It is something that is done with people, not to them. And the saying that "good teachers are born, not made" is nonsense. With the right attitude and good training almost anyone gifted enough to be a doctor, with the myriad of skills that involves, can become a good teacher. Indeed, most doctors teach their patients, as part of their normal clinical routine, although they do not usually regard this as teaching. Teaching other doctors, rather than parients, simply changes the emphasis on content, method and outcome.

The best teachers recognise that different individuals have different learning styles, even wichin a relatively homologous group such as paramedics, ophthalmologists or forensic psychiatrists. For example, some people are visual learners, others visual/ verbal learners, physical learners or auditory learners. Some people might have a preference for more than one of these learning styles, whereas a few might have no strong preference at all. Visual learners ate helped by visual material such as diagrams, flow charts, mind maps, photos and video clips. In lectures and other formal presencations, visual aids are very important to visual learners. Visual/verbal learners like written material. 'They, too, are helped by mind maps, but also enjoy learning through reading books and journals. They tend to be note-takers and also find well-prepared lecture handouts useful. Physical learners are often found to be the predominant group in healthcare. They tend not to learn very well from lectures because, being active learners, they want to roll up their sleeves and by physically involved with learning. Therefore, they do particularly well at practical learning activities using equipment such as manikins, ophthalmoscopes etc. However, physical learners can use written material more effectively if they ate encouraged to write their own margin notes, use highlighter pens etc. They often also find it helpful to have incomplete lecture handouts with parts that they have to fill in themselves. Finally, auditory learners. These are the people who enjoy good lectures, and are often good orators, too. They like listening to things, and find it particularly helpful to explain what they are learning in their own words. Auditory learners are good to have in discussion groups because they ate good at stimulating debate.

\section{CONCLUDING REMARKS}

Developments in medical education are taking place faster than ever before. The basic principles outlined in this editorial will remain sound for both undergraduate and postgraduate medical education, but the ways in which they are applied are certain to change. Many medical schools across the world now have modern curricula, so Doctors moving into postgraduate training will have more insight than previous cohorts into their own learning preferences, backed up by exposure to modern learning methods.

Over the last few years, the focus has shifted from modernising the undergraduate curriculum and is now very much on modernising postgraduate medical education and examinations. In this the UK, once so reluctant to make change, is now among the countries that are in the vanguard. The indicacors are that funure developments will ain to make the whole process of medical education more seamless from medical school through to Continuing Professional Development, and the examinations and assessments involved will be developed to ensure that they are as valid, reliable and fair as possible. We have come a very long way, but when it comes to teaching and learning in medicine thete is still a great deal more we can do. 